\title{
Only Connect? Older lesbian, gay and bisexual (LGB) adults and social capital
}

\begin{abstract}
The concept of social capital is widely used in the social sciences and has, to an extent, been applied to the lives and social networks of older lesbian, gay and bisexual (hereafter LGB) adults. Developing existing research, this paper argues that while not without its problems, the concept of social capital enriches our understanding of these networks, whilst simultaneously deconstructing the negative stereotypes surrounding homosexuality in later life. However, little attention has been paid to the social factors that mediate access and participation in lesbian and gay communities and the implications of this on the quality and experience of later life. Drawing on qualitative research conducted in the United Kingdom (UK), this paper illustrates how biography, gender and socio-economic status are significant mediators in the development and maintenance of social capital by older LGB adults. It concludes with a set of recommendations aimed at improving the social capital of older LGB adults, together with the importance of 'queering' the concept itself.
\end{abstract}

Key words: lesbian, gay, later life, sexuality, social capital, social networks. 


\section{Introduction}

The concept of social capital has been used extensively by social scientists and policy makers to explore the nature, role and value of social networks and community activities (Portes 1998). As Field (2008) notes, while not without its critics, it has been championed by both the political Left and Right as an analytical and political panacea, capable of resolving a variety of social problems in areas as diverse as crime and deviance, education, economic growth and health and well-being.

Despite considerable multidisciplinary research that has sought to make links between different levels of social capital and a range of social, political and economic factors, very little research has explicitly explored sexualized forms of social capital. There are some notable exceptions to this. Weeks, Heaphy and Donovan (2001) explored the social capital present in lesbian, gay and bisexual family and friendship networks, whilst others (e.g. Bell and Binnie 2004) have highlighted the links between social geography and queer spaces. However, there continues to be a lack of research focusing specifically on the social capital of older lesbian, gay and bisexual adults (hereafter older LGB adults). In keeping with existing research practices in this area we define older as 50 years of age and over.

Gerontologists, together with those in allied disciplines such as social work and social policy, have begun to consider the effects of social support and social networks on the health, well being and quality of life of older LGB adults (e.g. Grossman, D'Augelli and Dragowski 2007, Richard and Brown 2006, Shippy, Cantor and Brennan 2004). However, most of these studies are based on 
research undertaken in the United States (US) and do not, of themselves, problematise the concept of social capital when applied to older LGB adults' lives. The aim of this paper is to ameliorate this omission. In effect, it attempts to 'queer' social capital by exploring the complex social networks and relationships of older LGB adults based in the United Kingdom (UK).

The paper begins with a brief overview of the concept of social capital, noting some general problems with its theorisation. It then considers the significance of social networks to LGB communities, before focusing on social networks and support amongst older LGB adults. After a brief discussion of methodology, we focus on the findings from biographical research we conducted in the UK. These findings show how individual biography, gender and socio-economic status mediate access to and participation in social networks and hence degrees of social capital. They also demonstrate how sexuality and age affect connections with wider community and society. The final section draws the key points of the preceding sections together, considering their ramifications for policy makers and practitioners, as well as the need to reconsider our understandings of social capital itself.

\section{The Concept of Social Capital}

The current academic and political interest in social capital rests primarily with the work of Bourdieu $(1984,1988)$, Coleman (1994) and, Putnam (Putnam 1993, 1995, 2000). While not dismissing the importance of Coleman's work, the discussion here focuses primarily on the work of Putnam and Bourdieu. 
Putnam defines social capital as the "social relationships, expectations, obligations and norms that contribute to produce human activity" (1995: 67); a definition that potentially opens up the space for a wider investigation of social networks. For Putnam, social capital is about the value of locally situated social networks - the 'social connectedness' - that exists between individuals, communities and wider society and the benefits that follow from these connections at both an individual and collective level. Social networks assist in the development of trust and norms of reciprocity; hence, it is assumed that people living in a community with high levels of social capital will be at a social advantage compared to those living in a community devoid of it. Furthermore, unlike the finite nature of physical resources, the use of social capital leads to the production of more social capital, thus leaving a community enriched.

Putnam (1993) has distinguished different dimensions of social capital, including horizontal associations, those between people of similar status, and vertical or linking associations, those that are more hierarchical. Developing his thesis further, Putnam (2000) identified two sorts of social capital that he believed were crucial: bonding and bridging. The former refers to relationships within a group, while the latter to relationships linking a specific group to other groups and wider society. Horizontal and vertical associations may be present in both, although the latter may predominate in bridging social capital.

Putnam argues that bonding is important for underpinning reciprocity and solidarity, whilst bridging provides links to external assets, assisting in information diffusion and helping to create broader identities compared to the narrower identities associated with bonding social capital. Putnam asserts that 
these capitals are not exclusive, where the existence of one infers the lack of another. For instance, he acknowledges the significance of both in the leading role of the church in Black communities as an example of strong bonding social capital. Nevertheless, he warns against the effects of very high levels of bonding social capital, fearing that strong in-group loyalty can lead to equally strong hostility to the out-group, creating a 'dark side' of social capital (Putnam 2000: 350).

It is not possible, or necessary, to produce a full critique of Putnam's thesis within the confines of this paper. However, two criticisms of his work, related to gender norms and his narrow view of the geo-spatial aspects of identity echo those we will make in relation to the social networks of older LGB adults.

For some feminist writers, Putnam's conceptualisation of social capital reflects a conservative patriarchal view of society that is largely based on an out-dated American model. He ignores the gendered nature of networks and the cultural and geo-political specificities of their development; women will have differential access to social networks compared to men in various contexts (Molyneux 2002). Indeed, Putnam fails to recognise that women's social networks have moved from the private space of the home and neighbourhood to the public space of work (Skocpol 1996). In this respect, Putnam's theory has much in common with other social consensus theories, which are ultimately flawed because they do not consider the unequal social distribution of power. In this instance, patriarchal forms of social capital may be beneficial for maintaining the status quo, but it is not necessarily a status quo that benefits women, or to broaden the argument, any other marginalized group. 
Arguably, Putnam's theorization of social capital is based on a largely heteronormative set of assumptions concerning the life trajectories of women and men. By heteronormative, we mean the belief that sex, gender and sexuality are inextricably linked and that heterosexuality is normal, natural and the pivot around which society is organised (AUTHOR A AND B 2010a). Heterosexuality is viewed as the dominant mode for sexual relationships and consequently linked to traditional understandings about how men and women should behave e.g. gender roles, family relationships etc.

While few studies have explicitly analysed sexualized forms of social capital, it is, in its present formulation, a sexually conservative concept. In using it to understand the social networks of older LGB adults, it is therefore necessary to move beyond the heteronormative assumptions currently underpinning its use, as we will demonstrate later in this paper.

A second problem concerns Putnam's view of social capital and community. Studies of ethnic minority communities (Campbell and McLean 2002) demonstrate that trust and reciprocity networks do not exist de facto because of shared locality, but rather develop based on shared identity and interest. Meanwhile, research on electronic networks (Sullivanet al. 2002) challenge Putnam's geographically situated formulation. Once again, these studies indicate that Putnam's view is 'normative' and exclusionary. For example, lesbian and gay social networks, which are based on a sense of shared identity and despite the existence of 'gay enclaves' are often geographically dispersed, have successfully utilised the Internet for both political and personal networking (Wakeford 2000). 
These criticisms indicate that Putnam's understanding of social capital ignores structural inequality, marginality and reinforces the status quo. The utopian myth of communities, who have a shared value system and strong traditional support systems, is only made possible by either excluding or rendering invisible particular groups, who present a challenge to the myth. Thus, while not redundant, the distinction between bonding and bridging forms of social capital is useful, but only when greater attention is paid to the distribution of power. It is here that we turn to the work of Pierre Bourdieu.

Bourdieu's $(1984,1988)$ work on social capital, with its links to socially acquired ways of being (habitus), social status and inequality, is often regarded as being theoretically more sophisticated and politically more radical than the work of Putnam. Originally developed from his study of social reproduction amongst Algerian tribespeople, it was extended in his later works to address social distinctions in French society (Field 2008).

For Bourdieu, social capital is a means of gaining advantage in the social world; individuals and social groups exploit connections, primarily to achieve and maintain social standing. The significance of Bourdieu's conceptualisation is his insistence on the relationship between social capital and other forms capital, such as knowledge (cultural capital) and, ultimately, economic power (economic capital) (Portes 1998). Indeed, a lack of attention to this complexity is seen as a particular problem in Putnam's work (Edwards and Foley 1998). However, Bourdieu's adherence to a structural framework, influenced by Marxism, in which social capital is the property of ruling elites, has its limitations. As Field (2008: 22) notes, it does not allow for the "possibility that other less privileged 
individuals and groups might also find benefit in their social ties". Furthermore, the lack of attention to individual agency produces a "static model of social hierarchy" (Field 2008: 20), which contains little possibility for change.

In both Putnam's and Bourdieu's conceptions of social capital there is then a tension between individuals and society, which may be especially significant for those who are marginalised, such as the old and those who are not heterosexual. Ironically, although the significance of social networks and support amongst older LGB adults has been subject to academic scrutiny, as we discuss below, this has not resulted in a reconsideration of social capital itself.

\section{LGB Communities, Social Networks and Ageing}

The birth of the modern Gay Liberation Movement in the early 1970s played a vital role in the development of both lesbian and gay identity and community (Altman 1982, Weeks 1977). Until this point, apart from the 1967 Sexual Offences Act in the UK, reform had been patchy and hindered by the lack of an organised movement demanding political and social change. In the 1960s, homosexuality was routinely treated with aversion therapy and it was not until 1992 that the World Health Organisation declassified it as a mental disorder. The Stonewall Riots in New York in 1969 provided the impetus for political action in both the US and UK, leading to the 1970s becoming the "turning-point in the evolution of a homosexual consciousness" (Weeks 1977: 186). Gay Liberation demanded change in the political, judicial and social treatment of lesbians and gay men, signalling the birth of a modern lesbian and gay culture, which in its contemporary form provides a diverse range of health, leisure and entertainment, financial and legal services. 
Despite continuing institutional and personal discrimination, four decades of political activism, alongside changing social attitudes, has been beneficial. Recent legislation, such as the Civil Partnerships Act (2004), the Equality Act (Sexual Orientation) Regulations (2006) and the Equality Act (2010) are indicative of a more tolerant, if not always accepting, society. However, the dominant institutional and cultural framework remains heteronormative and the continuing occurrence of homophobic hate crimes is a stark reminder of the lack of tolerance in some sections of society. It is in relation to these changing conditions that current cohorts of older LGB adults have lived their lives.

It is difficult to ascertain how many of the older population are lesbian, gay and/or bisexual. Based on the estimate that 6.5 per cent of the total UK population is 'exclusively homosexual', Age Concern (2002) suggest that 1 in 15 of their services users will be LGB. Despite a growing awareness by academics, policy makers and service providers of the socially diverse nature of the older population, older LGB adults have traditionally either been ignored within gerontology or represented as socially isolated due to social and familial rejection (Fokkema and Kuyper 2009, Kehoe 1991).

Other evidence, however, problematises this suggestion. While accepting that older LGB adults are less likely than heterosexuals to receive support from family members, they do receive high levels of social support from friends, leading Dorfman et al (1995) to coin the term 'friendship families'. Such claims are not just limited to later life, but form part of the current debate on LGB relationships across the life course (Heaphy 2009, Weeks, Heaphy and Donovan 2001, Weston 1991). These and other studies, particularly those in the field of 
gerontological social work (e.g. Hash and Netting 2009, Shippy, Cantor and Brennan 2004), indicate that LGB adults have a freedom to create their own family networks from partners and friends . As Dorfman et al (1995: 40) noted:

"Perhaps being a homosexual in a predominantly heterosexual culture serves to strengthen bonds between gay individuals, thus enriching [friendship] family networks."

However, research has also challenged the assumption that older LGB adults are not involved with their biological families, either in terms of affective relationships or as carers (Shippy, Cantor and Brennan 2004). Thus, all of these studies indicate that LGB adults develop extensive and significant social networks over their life course, which affect their experiences of ageing.

It is, however, important to temper such a uniform and to an extent positive conclusion, because other research findings (AUTHOR A 2004, (Heaphy 2009), indicate that access to and participation in social networks is uneven and related to other significant factors, such as geographical location and already existing LGB social networks (Bell and Valentine 1995). Such conditions will have a particular salience in later life. Considering the increased life expectancy enjoyed by adults in the UK, later life covers an increasingly extended period of the life course. It is likely to include periods of employment and retirement, as well as changes to income, health, family and friendship ties. Furthermore, the sociohistorical context in which current cohorts of older LGB adults reached sexual maturity will also affect their experiences of later life, an issue elucidated in both Rosenfeld's (2002) study of older LGB adults and developed in AUTHOR A's (2004) study of older lesbians. 
Rosenfeld (2002) identified two 'identity cohorts', which may affect later life experiences. The first cohort, primarily consisting of the 'old-old', includes adults who became aware of their sexuality before the Gay Liberation Movement. Lacking an alternative meaning, many of these LGB adults internalised the dominant cultural understanding of homosexuality as pathological and deviant, leading some to develop poor self-image and low self-esteem. Within this hostile climate, it was expedient for lesbians and gay men to adopt lifelong survival strategies such as secrecy and 'passing' (for example, in their dealings with officialdom, including health and social care services). Despite a liberalisation of laws and changing cultural attitudes towards homosexuality, research suggests (Langley 2001, Rosenfeld 2002) that it is likely that this group of 'old-old' LGB adults will continue to be secretive about their sexuality in later life, thus making social isolation more likely.

In contrast, Rosenfeld's second 'identity cohort' consists primarily of the 'youngold': women and men who embraced a lesbian or gay identity and lifestyle either during Gay Liberation, or in the period directly following it. This group had access to a self-affirmative and celebratory discourse, thus affecting their conceptualisation of their sexual identity. This group is more likely to be visible, belong to social networks and communities and lobby for services.

Despite the usefulness of these cohorts, they do not address the experiences of women (and men) who adopted a non-heterosexual identity and/or lifestyle later in life (AUTHOR A 2004) and hence may form a third identity cohort, which may cut across age boundaries. AUTHOR A suggests that older women, who did not adopt a lesbian lifestyle until later in life, often following heterosexual 
relationships and raising children, may find it difficult to access and participate in lesbian networks and communities. The major barrier to participation for these women is the lack of a locally based lesbian network and an inability to move to one due to either a lack of financial resources or existing family ties. This situation is particularly acute for women with children still living at home and/or those who are not in paid employment. These women find it extremely difficult, if not impossible, to either initiate an intimate relationship or become involved in lesbian and gay networks. Thus, the use of the Internet may become an important access point to lesbian networks. Such findings both point to the diversity of experience and cast doubt over the validity of assuming that sexual identity is fixed and unchanging.

Evidence suggests that older LGB adults experience several challenges in their connections and networks external to LGB communities, such as social institutions and service providers. Research conducted in the US and UK, suggests that older LGB people face discrimination and inequality when attempting to access housing, health and social care services (Heaphy and Yip 2006, Hunt and Minsky 2005, Richard and Brown 2006). Hence, their ability to draw on wider social networks and forms of support is, perhaps unsurprisingly, affected by the heteronormative nature of social institutions (Fish 2006). This can lead to a lack of trust, confidence and ultimately affect the possibility of developing and maintaining bridging social capital.

To summarise, previous research indicates that far from being socially isolated, older LGB adults are embedded in a variety of social networks and are able to develop and maintain bonding social capital, although the extent of developing 
bridging social capital is more problematic. However, we contend that such conclusions must take account of the complexities of people's biographies and identities. Only then can we assess if social capital is a valid concept when considering the relationship between ageing and sexuality. In the remainder of this paper we report on our own research findings, to illustrate these points. Firstly, however, we briefly outline the methodology of our own study.

\section{Methodology}

\section{The Sample}

A sample of 22 adults (11 men and 11 women) aged between 50-73 years old, were recruited for a project conducted in 2008/09, which examined sexuality in later life. The majority of these participants were based in a large city. Thirteen were employed full-time, two employed part-time, one was registered disabled and six were retired. Participants represented a range of socio-economic statuses. Twenty-one participants were White; one man was Mixed White/Black British. We experienced considerable difficulty in recruiting participants from Black and Minority Ethnic (BME) communities. Previous research has also experienced these sampling issues (Davies and River 2006), leading to the conclusion that in order to adequately sample these populations in future research more time and resources than were available in the project discussed here would be required.

\section{Data Collection}

Participants were recruited by convenience and snowball sampling (Bryman 2004). Leaflets and letters were sent to a diverse range of LGB organisations and 
venues. Following research concerning the use of the Internet by LGB adults, we recruited a number of participants via LGB message boards and social networking sites. Each interview lasted between sixty and ninety minutes and an interview schedule used open-ended questions, focusing on: individual biography; 'coming out' experiences; understandings of identity; attitudes towards ageing; participation in lesbian and gay social networks and communities; and use of the Internet.

\section{Data Analysis}

We used a combination of thematic and narrative analysis to analyse our data. Coding was undertaken with NVivo software to facilitate access to data and inter-rater reliability (Bryman 2004). A range of themes and issues arose during both interviews and data analysis, this paper, however, focuses on access to and participation in friendship groups and wider social networks as ways to develop and maintain bonding and bridging social capital.

\section{Biographical past and present}

Older LGB adults, like their heterosexual counterparts, are embedded in a range of social networks. However, as suggested above, their ability to develop and maintain these networks is mediated by their biographies, past and present.

It is often assumed that a current identification as lesbian, gay or bisexual reflects a lifetime's identification with the label. Although the majority of our participants experienced same-sex attraction when young, only a minority had felt able to develop a homosexual lifestyle. This was due to a combination of negative parental attitudes and awareness of society's attitude towards 
homosexuality at the time. Most did eventually 'come out' to parents and close family, with a few reporting that initial hostility and denial later softened to reluctant tolerance and occasionally full acceptance. Only one man reported that his parents had always accepted his homosexuality unconditionally.

The reaction of family members was further complicated for our male participants by the lack of legal status accorded to male homosexuality before its legalisation in 1967. This profoundly affected their lives and their relationships with their family, as well as their ability to be open about their sexuality. Moreover, this was even the case for some members of our sample who were in Rosenfeld's (2002) 'young-old' identity cohort, such as Stephen:

"When I was young it was illegal so it was definitely not something one discussed at school or at home, definitely not with my parents anyway. So I had to be secretive about it and I've only become more open about it in my later life when things have become more, [...] open." (Stephen, 55-59)

Here Stephen indicates that his ability to develop relations of reciprocity and trust with other gay people was not something that had spanned his life; a story that was not unique amongst our sample. Indeed, a negative view of homosexuality had led many of our participants to engage in heterosexual relationships, either short term or long term, some of which included raising children, thus illustrating the importance of AUTHOR A's (2004) third identity cohort. One man had remained married despite being in a long-term relationship with a man, although it was noticeable that more women than men in our study had been married. 
An individual who may 'come out' in later life faces the additional burden of possible rejection by children, as well as having to tell a spouse, family and friends. Participants mentioned loosing lifelong friends, while those with children met with mixed reactions, ranging from initial to long-term hostility. Other children were more accepting from the beginning, although two participants, fearing the consequences, had not yet told their adult children. Hence, the bonding social capital they developed may have been highly specific and contextual, focusing on a few well-chosen LGB friends, rather than the wider LGB community.

Those participants, who had not engaged in heterosexual relationships during their adulthood, had often delayed the 'coming out' process until after they had left their family home. For one male participant this happened at the age of 21 in the context of theological college:

"I went to theological college (...) and there were gay and gay identified staff $[\ldots]$, and 40 per cent gay ordinands [...], so [...] they at least provided me with the first positive environment in which I could relate to other gay people of my own age. [...]. So I began to feel very positive about my sexuality in 1972, 1973, which of course coincided with Gay Liberation, [...] and that was very exciting to see what was happening, so I drew myself in, got drawn into some of these activist networks and it really did speak very powerfully to something that I had previously not been very aware of." (David, 55-59)

David's story illustrates the point that entry into a subculture, which holds a positive view of homosexuality, can enable an individual to 'come out' to both 
themselves and others, enabling them to develop the norms of reciprocity and trust central to bonding social capital. Indeed, some of our participants stated that leaving home and becoming involved with LGB organizations felt like they were 'coming home'. This was, however, denied to those adults who did not feel able to express their same-sex feelings or who were unable to access LGB organizations.

The majority of our participants had not been able to develop strong and supportive relationships with parents and close family members. Contrary to the evidence of other studies (Shippy, Cantor and Brennan 2004), most of our participants stated that they were unlikely to call on parents for support due to their age. Nor did they expect to rely on extended family members, or possibly even adult children, in terms of social support later in life. One woman felt that there was an invisible barrier between her and her family, which meant she was not able to turn to them for help. Many participants appeared to accept this lack of support in a matter of fact way, while others acknowledged the difficulties this presented, particularly in the case of the single women and men in the study. Despite this, several participants were caring for their parents, often at the expense of their LGB friendships and networks. Again, if this is framed in terms of social capital these individuals effectively lacked both the bonding social capital provided by family connections and the reciprocity and shared norms provided by the wider LGB community. They were, in this respect, doubly marginalised.

In terms of marginality, relationships with partners and friends can form a significant mediating factor, providing psychological and other supports (Heaphy 
2009). Thirteen of our participants were in a long-term relationship: seven men and six women, ranging from six to thirty years. Several of the men were in civil partnerships and all participants talked positively about their relationships and expected that they would provide mutual support later in their lives. The remainder of the sample were single. The single women stated they would prefer to be in a relationship, yet they lacked the opportunity to meet a potential partner. In contrast, the single men were more circumspect about their relationship status, valuing the freedom of independence that it granted them. It was noticeable that participants in long term relationships expressed more positive attitudes towards ageing than those who were single.

Regardless of relationship status, all participants reflected previous research findings that friendship was important, even if they did not have an extended friendship network. Most expressed a preference for friends of their own age, feeling that they were likely to have more in common with them and, in the case of long term existing friendship networks, there was the added advantage of a shared personal history. However, a preference for friends of a similar age was not always possible. One single woman belonged to the local branch of a national lesbian social network, its membership consisting of women much younger than her. While she used to have friends her own age a number of factors had led to the loss of these friendships leaving her feeling isolated and disconnected from older lesbians:

"I'm finding it very difficult with friends because I do make friends but then one died, others are moving away. Everyone's sort of moving around. And there are others that are in relationships; they are having their life [...] Yes, 
all my old friends have dropped away, one way or another [...] compared to how it was when I was younger it's totally, totally different. And not what I'd have chosen." (Sandy, 60-64)

Sandy's story is not unique to older LGB adults; many heterosexual people could find themselves in a similar position. However, by reading Sandy's story through the lens of social capital, together with those of a similar nature, we should question the extent to which all LGB adults have access to 'friendship families' or 'families of choice' in later life. One participant, Anthony, who discussed two friends, one who was in hospital and another who had been married but now identified as gay, illustrated this. The former lacked friends because he had not been able to accept his own homosexuality and therefore had little contact with the wider LGB community:

"I know somebody else who has just gone into hospital as a result of a health crisis he had last week, and I'm the only person that goes and visits him. He's the same age as me, and it's because he's had that kind of, internalised homophobia thing." (Anthony, 50-54)

In this respect, his experience of later life was marked by a lack of bonding social capital. In contrast, the second man Anthony identified was embedded in a range of networks, including those in wider the LGB community:

“He has a whole kind of network of people from all different places and he's very good at being proactive in keeping in touch with people and getting different groups of people together." (Anthony, 50-54) 
This man's story indicates the complexity of developing and maintaining social capital for some older LGB adults, highlighting how in later life networks transcend simple definitions about sexuality.

For many older LGB adults, friends may act as their first source of support or help, sometimes taking the place of more institutionalised forms. As Leonard noted:

“Oh I wouldn't go anywhere else I wouldn't go to any social services agency unless it was for something really practical like I need to go to the Red Cross to borrow a pair of crutches something like that. [...] I think it's sort of an unspoken [...] we know that we are going to support each other, I mean we've supported each other financially, we've lent money to each other, there's a tremendous amount of trust [...]. You know five or six of us together it's sort of unconditional [...] my sort of, network it's just purely my gay friends and then through that network we will do holidays together." (Leonard, 55-59)

While Vanessa stated:

"I would in regards to being older rely very much on my friends, it's different if you have got a partner when you get older you tend to rely on that person [...] but as I said the important thing is friends, lovers tend to come and go." (Vanessa, 60-64)

Both Leonard and Vanessa indicate the importance of trust and reciprocity and the horizontal associations that Putnam describes as important for developing and maintaining bonding social capital. For older LGB adults this is especially 
salient because the heteronormative organisation of society means that many, but particularly older gay men, have developed closer friendship networks than perhaps they would otherwise have done. Additionally, some of the older gay men in our study explained that their friendship networks were often smaller than they might have expected them to be at their age due to the impact of HIV/AIDS. Conversely, the experience of losing friends through HIV/AIDS had led to a strengthening of bonds amongst remaining friends, and for some men, involvement in HIV/AIDS organisations, ultimately leading to new friendships. While this demonstrates the positive aspects of friendship for older LGB adults, it remains the case that a number of our participants lacked friends and felt isolated.

\section{Intersecting Identities- gender and socio-economic status}

Thus far we have indicated how an individual's biography mediates their ability to generate and preserve the bonds that Putnam viewed as central to well-being. It is important, however, that we do not retain an overly individualised view. Older LGB adults, like all older people, have a multiplicity of identifications and as we have discussed elsewhere are situated at the intersection of many social divisions (AUTHOR A \& B 2010b), including those related to both gender and socio-economic status.

There is a tendency for the representation of older LGB adults to emphasise outgroup differences and ignore the vertical differences within LGB communities. Certain groups have been over-represented in research: middle-class, white gay men (Davieset al. 2006). Moreover, references to a 'gay community' can obscure differences in the financial status of lesbians compared to their gay and bisexual 
male counterparts (Price 2005). Factors affecting socio-economic status, such as unemployment, illness and disability may also disproportionately affect members of the LGB community: for example, the potential of HIV to reduce income through needs of care support and ill-health (Munro 2002). It has also been noted that, until recently, access to certain benefits enjoyed by heterosexual couples have been denied to LGB adults (Age Concern 2002). Even with the introduction of the Civil Partnership Act (2004), certain forms of financial disparity remain, especially for those who do not enter such legal partnerships. In this respect, these intersecting factors mediate simple notions of whether older LGB adults have, or do not have, stocks of social capital. This can be illustrated by differential experiences in relation to retirement.

A number of our male participants had chosen to take early retirement in order to pursue leisure activities and hobbies previously deferred due to a lack of time. Early retirement was only made possible by their own economic capital or that of an employed partner. Thomas, for example, expressed a very positive, carefree attitude towards later life:

"I am buffeted by the privilege in so far as I am living with someone who is earning a full time salary and doesn't resent our money, well his money being considered to be part of the common pot, as mine was when I was earning, [...] and I do have a certain degree of financial independence, which many people are not is the same fortunate position as I am to benefit from... I want to see what life throws at me." (Thomas, 55-59)

Thomas' ability to engage in social networks and extend his social capital was both gendered and related to his economic circumstances. However, not all male 
participants shared this positive experience. One single man talked about the depression he initially suffered on retirement, in part due to a lack of purpose and loss of a work identity. However, the route out of depression for this man was involvement in gay community groups, together with involvement in local church groups:

"I think it was the loss of job and the loss of identity through the loss of job which was a major factor. And I did go through a period of considerable depression as a result of that. And it was being conscious of the depression that made me feel 'well I've got to pull myself out of that', and the way to do that is to broaden my horizons and get more involved in various things that are going on within the community." (Paul, 70+)

The retired women, both partnered and single, welcomed the freedom from work, yet a lack of finance curtailed their involvement in activities that involved expenditure. One woman, not in a relationship and past retirement age, had returned to part-time work for financial reasons. Women currently employed expressed similar concerns about the future; particularly single women and women who had been married and unemployed for large parts of their adult life, again demonstrating AUTHOR A's (2004) third identity cohort effect. This is not to deny poverty amongst older gay men, but recognition that gender will exacerbate this situation.

It is clear, therefore, that access to social networks and to developing and maintaining social capital is not straightforward for older LGB adults, differences abound. It is for this reason that Bourdieu's conception of social capital, its relationship to other capitals and thus power remains a useful adjunct to 
mitigate the more optimistic representation suggested by Putnam. This is further illustrated in our data when we turn to consider older LGB adults' connections to wider social networks and institutions.

\section{Identity, Community and Social Institutions}

The ability to create bonding social capital and also to build bridges to other communities requires the provision of places and organisations where older LGB adults can meet and socialize safely. We have already discussed participants' involvement in LGB focused organizations; although we would wish to add here that many participants felt that there while there were voluntary organizations catering for the needs of older LGB adults, there needed to be dedicated social space in which they could meet. This is particularly important for adults who either have not been able to develop strong friendship networks during the course of their life, or due to changing circumstances, no longer have access to these friendships. It might be reasonable to assume that this would be facilitated by the commercial gay scene. However, here again forms of exclusion exist which impact on older LGB adults. While all the participants of our study expressed the view that the commercial gay scene is youth orientated and hence ageist, there was a difference in this view according to gender and to a lesser extent relationship status. Here then we can see the interaction between social capital and other forms of capital, particularly economic and human capital, making Bourdieu's theorisation of the interplay between capitals more significant.

Women expressed the view that the commercial gay scene was both ageist and sexist, in that much of it catered to the needs of younger gay men. This was 
further complicated by the expense of the gay scene; older lesbian women, either retired or on a low income, could not afford to participate.

Some of the older gay men felt excluded from the scene because of their age, or to be more specific, their ageing bodies. While men in long term relationships and/or who had extended friendship networks did not regard this as a major problem, it was more problematic for single men who viewed it as an important space to meet new men, either for friendship or a relationship.

Despite the problems of the commercial gay scene, a number of the single gay men we interviewed did make use of it. One gay man worked and socialised on the scene in way that would have been antithetical to his identity when he was younger.

Whatever their experiences of the wider LGB community, all our participants were embedded in networks involving non-gay organizations and their local communities. Several of our participants were active in various community groups outside of the gay community, such as activity classes, religious organisations and leisure pursuits. When discussing these, we asked our participants to consider if their sexuality affected their membership of these groups. In effect, we wanted to ascertain if their sexuality excluded them from wider social network and precluded them developing forms of bridging social capital. One lesbian participant reflected on her experiences of an older persons support group she had joined. When asked if she would join another she responded: 
"It was all cliquey and the others just sit down there on their own. I think the worry is that that culture is also in [older person's charity], but it might not be." (June, 60-64)

June raised a series of important points about the provision of services for older people, being especially critical of what she perceived to be the heteronormative nature of these groups. She cited conversations she had engaged in with members of groups she had joined as evidence:

"I did in a strange way feel excluded. I never got included let's put it that way. It's more subtle than being excluded. It's just you don't get included, it's very subtle. And I find that they are all very cliquey. Because they all meet up and well they have this language of grandchildren and 'my daughter did this and my daughter did that'. There's just nowhere to go with it for me." (June, 60-64)

Moreover, June had been concerned about the reactions of others should she have revealed her sexuality, although she did not know for certain that she would experience a hostile reaction. It is, therefore, clear that older people's services should be able to reflect and welcome all sections of the community, including older LGB people, thus building norms and trust related to equality. This was affirmed by the experience of one gay man who belonged to a number of church groups, who suggested that he did not get too closely involved with these groups: 
“They get very deeply involved in each other in a way that I wouldn't necessarily, partly because I do get a sense of their not being entirely welcoming to homosexuals." (Nigel, 70+)

Many felt that, unlike their heterosexual counterparts, there was less opportunity for them to develop friendship in their local neighbourhood because of their sexuality.

"But because you have to go out and make your friends in the gay community because most of your socialising is out of the house, going out to a club or going out to a bar or whatever or joining the outdoor walking group or whatever, but it's all about active participation rather than the next door neighbour or whatever, but that depends on where you live [...] it depends on how well you get on with your neighbours full-stop, but if you lived in a gay neighbourhood maybe there will be a bit of gay neighbourliness in later life, it's difficult to tell but that would only carry on if it existed already I suppose." (Geoff, 50-54)

Geoff's experience indicates that attempts to form connections within a local community or neighbourhood, thereby developing bridging social capital, are affected by sexuality and the existence, or otherwise, of bonding social capital. The two are inextricably linked and highly contextualised.

\section{Discussion and Conclusions}


Our aim in this paper has been to examine the network of connections that older LGB adults are embedded within. We have used, therefore, the lens of social capital to frame and understand these connections. In so doing, we have argued that this means we need to 'queer' the conceptualisation of social capital. In this final section, we draw together the key findings from the above discussion, to consider its ramifications for improving the lives of older LGB adults, in terms of developing their social capital, and also assess what this means for the concept of social capital itself.

Our research would suggest that older LGB adults, who are able to participate in community activities, offer and receive support, have been able to foster feelings of belonging. They are secure in the knowledge that they can draw on a range of friendship and community based resources if necessary. In other words, these networks demonstrate characteristics of social capital: social trust, solidarity and norms of reciprocity, both general and specific. They can also act as a buffer against the stresses of living in a heteronormative society.

In this respect our findings support earlier 'gay-affirmative' research, while the use of social capital extends the sociological understanding of older LGB adults and addresses the social organisation and regulation of sexuality. Far from being depressed and socially isolated, adults who belong to social groups enjoy high levels of social support and bonding social capital, thus affirming the suggestion that these adults maybe better placed to face the challenges of later life than their heterosexual counterparts (Richard and Brown 2006, Shippy, Cantor and Brennan 2004). However, the reverse exists for adults who are not able to gain access to and participate in LGB culture. 
This situation is exacerbated by a commercial gay scene that is perceived to be ageist, expensive, and in the case of women, sexist. While some of the older men did use the commercial gay scene to make friends, the majority of our participants no longer frequented commercial gay-spaces. These forms of vertical distinction demonstrate the importance of the provision of non-profit making venues and social spaces for older LGB adults. In our opinion, Local Authorities need to make available dedicated social space for older LGB adults. This would be in keeping with existing policy that recognizes that other minority sections of the older population need specific provision.

Finally, and addressing the issue of bridging social capital, we turn to matters relating to the use of non-gay space or organizations. As our discussion of social capital makes clear, these types of organisation are a vital source of social support for older LGB adults. It is therefore extremely important that older LGB adults feel welcomed in these organisations and certainly that they do not feel they are being discriminated against because of their sexuality. Local authorities should ensure that any instance of homophobia in organisations it runs or sponsors is investigated and acted upon. Likewise, those running these organisations need to be made aware of the importance of developing an inclusive and welcoming environment. Reducing heterosexism in these environments is essential, as failure to do so will in all likelihood result in older LGB adults avoiding these organizations.

One key way in which community organisations can demonstrate inclusiveness is by displaying material that is directly aimed at older LGB adults. Many of our participants commented on the fact that the very lack of material aimed at them 
contributed to feelings of invisibility. Conversely, organisations that did display material aimed at LGB adults not only increased feelings of inclusiveness but also lead to greater confidence in being out about their sexuality.

Before we consider the implications of our analysis for the conceptualisation of social capital more generally, we should note some limitations with our study. Our convenience sample, although stratified for gender, was largely drawn from an urban base. In future, older LGB adults from suburban and rural locations should be sampled more comprehensively. Similarly, we were unable to stratify our sample to include many of the 'old-old' (Rosenfeld 2002), particularly those over eighty years of age. This may be particularly pertinent, not only because of the factors noted by Rosenfeld, but because Putnam (2000) regarded this generation as having greater stocks of social capital. Despite these limitations, our analysis demonstrates the usefulness of applying social capital to frame older LGB adults' lives. However, taking their experiences into account means reconsidering what is social capital.

\section{Queering Social Capital}

We have demonstrated how accessing social networks and social support is compounded by age and sexuality. As indicated in our analysis, the extent to which an individual expressed a positive attitude towards ageing was dependent on a number of key inter-related factors, concerning their biography, their financial status, friendship networks and wider social networks. We have illustrated how an individual's ability to form bonds of reciprocity and trust within a community, is crucial. Developing horizontal associations with other LGB adults can alleviate feelings of isolation and provide tangible supports in 
later life. Thus, Putnam's conceptualisation of bonding social capital and its links to well-being appear to be confirmed. However, as we have also demonstrated, other social identities, particularly gender and socio-economic status, are mediating factors that mean that inequalities exist within this group of adults. Indeed, elsewhere (AUTHOR A \& B 2010b) we have asserted that the very category older LGB is unsustainable, unless differences are taken into account.

In terms of social capital, we have therefore drawn on Bourdieu's conceptualisation, which emphasises power differentials and the relationship between social capital and other capitals. Some of the older LGB adults we interviewed had high levels of social and economic capital and therefore could use these to fulfil their needs in later life; as we noted, this was particularly so for the gay men in our sample. To an extent, therefore, these capitals may alleviate homophobia and heterosexism in older people's services. However, it is not simply that we should apply the idea of social capital to older LGB adults' lives, but we should use sexuality, and indeed ageing, to reconfigure our understandings of social capital. Whilst older LGB adults will share many experiences, in terms of social networks and associations, with older heterosexual adults, they will also have unique experiences. Where older heterosexuals may have developed networks and associations across their life course, older LGB adults, as we have demonstrated, face different challenges. People do not 'only connect' - they do so in relation to structural social factors, of which the interaction of ageing and sexuality within a heteronormative society, are highly significant determinants. 


\section{References}

Age Concern. 2002. Issues Facing Older Lesbians, Gay Men and Bisexuals. Available online at

http://www.ageconcern.org.uk/AgeConcern/Documents/OLGMppp.pdf (Date accessed 04/02/08).

Altman, D. 1982. The Homosexualization of America. Beacon Press, Boston.

Bell, D. and Binnie, J. 2004. Authenticating Queer Space: Citizenship, Urbanism and Governance. Urban Studies, 41, 9, 1807-1820.

Bell, D. and Valentine, G. 1995. Mapping Desire: Geographies of Sexualities. Routledge, London.

Bourdieu, P. 1984. Distinction: A Social Critique of the Judgement of Taste. Routledge and Keegan Paul, London.

Bourdieu, P. 1988. Homo Academicus. Polity Press, Cambridge. Bryman, A. 2004. Social Research Methods. Oxford University Press, Oxford. Campbell, C. and McLean, C. 2002. Ethnic Identities, Social Capital and Health Inequalities: Factors Shaping African-Caribbean Participation in Local Community Networks in the UK. Social Science and Medicine, 55, 4, 643-57. Coleman, J.S. 1994. Foundations of Social Theory. Belknap, Cambridge, MA. Davies, M., Addis, S., MacBride-Stewart, S. and Shepherd, M. 2006. The Health, Social Care and Housing needs of Lesbian, Gay, Bisexual and Transgender older people: literature review. Centre for Health Sciences Research, Cardiff University, Cardiff.

Davies, P. and River, L. 2006. Being Taken Seriously: The Polari in Partnership Project - Promoting Change for Older Lesbians, Gay Men and Bisexuals. Available 
online at $<$ http://www.casweb.org/polari/file-storage/> (date accessed $31 / 10 / 08)$.

Dorfman, R., Walters, K., Burke, P., Hardin, L., Karanik, T. and Raphael, J. 1995.

Old, Sad and Alone: The Myth of the Aging Homosexual. Journal of Gerontological Social Work, 24, 1/2, 29-44.

Edwards, B. and Foley, M.W. 1998. Civil Society and Social Capital beyond Putnam. American Behavioral Scientist, 42, 1, 124-139.

Field, J. 2008. Social Capital. Routledge, London.

Fish, J. 2006. Heterosexism in Health and Social Care. Palgrave MacMillan, Basingstoke.

Fokkema, T. and Kuyper, L. 2009. The Relation Between Social Embeddedness and Loneliness among Older Lesbian, Gay, and Bisexual Adults in the Netherlands. Archives of Sexual Behavior, 38, 2, 264-275.

Grossman, A.H., D'Augelli, A.R. and Dragowski, E.A. 2007. Care Giving and Care Receiving Among Older Lesbian, Gay and Bisexual Adults. Journal of Gay \& Lesbian Social Services, 18, 3/4, 15-38.

Hash, K.M. and Netting, F.E. 2009. It Takes a Community: Older Lesbians Meeting Social and Care Needs. Journal of Gay \& Lesbian Social Services, 21, 4, 326 - 342. Heaphy, B. 2009. The Storied, Complex Lives of Older GLBT Adults: Choices and its Limits in Older Lesbian and Gay Narratives of Relational Life. Journal of GLBT Family Studies, 5, 119-138.

Heaphy, B. and Yip, A.K.T. 2006. Policy Implications of Ageing Sexualities. Social Policy and Society, 5, 4, 443-451.

Hunt, R. and Minsky, A. 2005. Reducing health inequalities for Lesbian Gay and Bisexual people: Evidence of health care needs. Stonewall, London. 
Kehoe, M. 1991. Loneliness and the Aging Homosexual: Is Pet Therapy the Answer? Journal of Homosexuality, 20, 3/4, 137-141.

Langley, J. 2001. Developing Anti-Oppressive Empowering Social Work Practice with Older Lesbian Women and Gay Men. British Journal of Social Work, 31, 917932.

Molyneux, M. 2002. Gender and the Silences of Social Capital: Lessons from Latin America. Development and Change, 33, 2, 167-188.

Munro, I. 2002. The lived experience of gay men caring for others with HIV/AIDS: lliving, loving and dying in the era of HIV//AIDS. Unpublished PhD: Deakin University.

Portes, A. 1998. Social Capital: Its Orgins and Applications in Modern Sociology. Annual Review of Sociology, 24, 1-24.

Price, E. 2005. All but Invisible: Older Gay Men and Lesbians. Nursing Older People, 17, 4, 16-18.

Putnam, R.D. 1993. Making Democracy Work: Civic Traditions in Modern Italy. Princeton University Press, Princeton, NJ.

Putnam, R.D. 1995. Bowling Alone: America's Declining Social Capital. Journal of Democracy, 6, 65-78.

Putnam, R.D. 2000. Bowling Alone: The Collapse and Revival of American Community. Simon and Schuster, New York.

Richard, C.A. and Brown, A.H. 2006. Configurations of Informal Social Support Among Older Lesbians. Journal of Women \& Aging, 18, 4, 49 - 65.

Rosenfeld, D. 2002. Identity Careers of Older Gay Men and Lesbians. In Gubrium, F. and Holstein, J. (eds), Ways of Aging. Blackwell, Oxford. 
Shippy, R., Cantor, M. and Brennan, M. 2004. Social Networks of Aging Gay Men. The Journal of Men's Studies, 13, 1, 107-120.

Skocpol, T. 1996. Unraveling from Above. American Prospect, 25, 20-25.

Sullivan, J.S., Borgida, E., Jackson, M.S., Riedel, E., Oxendine, A. and Gangl, A. 2002. Social Capital and Community Electronic Networks, For-Profit Versus ForCommunity. American Behavioral Scientist, 45, 5, 868-886.

Wakeford, N. 2000. Cyberqueer. In Bell, D. and Kennedy, B.M. (eds), The Cybercultures Reader Routledge, New York.

Weeks, J. 1977. Coming Out: Homosexual Politics in Britain from the 19th Century to the Present. Quartet, London.

Weeks, J., Heaphy, B. and Donovan, C. 2001. Same-Sex Intimacies: Families of Choice and Other Life Experiments. Routledge, London.

Weston, K. 1991. Families We Chose: Lesbians, Gays, Kinship. Columbia University Press, New York. 